\title{
ALGUNS POSSIBLES TOPÒNIMS ÀRABS A LA PARTIDA DE BACAROT (MUNICIPI D'ALACANT)
}

\author{
Per \\ MARINELA GARCIA SEMPERE
}

Aquesta nota és part d'un treball més ample sobre la toponímia a la partida de Bacarot, del terme municipal d'Alacant (1). Sembla que alguns dels topònims recollits, sense un significat tan evident com el d'altres d'origen català, poden tindre una etimologia àrab. Així, el seu significat faria referència a l'antiga activitat agro-pecuària, i també a algunes característiques físiques de la zona.

El primer topònim que crida l'atenció és el nom mateix de la partida; el Bacarot - Bacarot, del qual encara no se n'ha donat una etimologia satisfactòria. En té una, de popular -bacora > bacorot > bacarot-segons la qual el nom es deu a que hi ha moltes bacores. Tanmateix és difícil que un mot derivat de l'àrab bākūra (fruita primerenca) com és bacora, haja evolucionat a un altre que duu /a/ on originàriament duia /u/.

Si busquem un possible origen llatí al terme, trobem que baca vol dir en llatí clàssic oliva, baia o perla (Diccionario Spes, 1978: 53), i baccar, -aris una planta d'arrel odorifera. En llatí vulgar pareix que baccalarius volia dir granger (Webster's Dictionary, 1983), i en catala antic bacallaria volia dir vilania o berganteria (Diccionari de la llengua catalana, 1987: 196). Sembla difícil relacionar aquesta etimologia amb el nom Bacarot.

EI Dr. Epalza ha estudiat l'arabisme baqar o albaqar que, segons ell, designava «... espacios para guardar el ganado, en las ciudades, en las fortalezas, en las huertas o en el campo en general» (Epalza, 1984: 48). A les fortaleses el baqar era una

(1) El treball és «Toponímia a la partida de Bacarot», presentat al XIVè Col.Loqui General de la Societat d'onomástica, I/n d'Onomàstica Valenciana, celebrat a Alacant els dies 13, 14 i 15 d'abril de 1989, i les Actes del qual es publicaran a desembre d'aquest mateix any. 
part del recinte, però sense cap construcció; a les ciutats n'era una part de l'estructura, on es guardava el ramat necessari per a la subsistència dels ciutadans, i al camp «Los albacares de las fortalezas rurales tendrían una función semejante, aunque en el estado actual de nuestros conocimientos, sólo se puede emitir la hipótesis más probable de que eran unos simples depósitos de ganado" (Epalza, 1984: 54). Potser Bacarot, per les característiques físiques de la zona, i per ser tradicionalment una zona ramadera, dega el seu nom a aquest ètim àrab.

Si observem un plànol de la partida, veurem que té uns límits naturals. Eixint des d'Alacant cap a Elx pel cami vell d'Oriola (és a dir, de nord-est a sud-oest), entrem a Bacarot creuant el barranc de les Ovelles. A l'esquerra separen la partida de la mar les serres del Porquet $i$ de Colmenars, i a la dreta trobem les serres de les Atalaies, les Llomes i lo Minyana. Eixim de la partida pel portitxol, un pas que es troba ja al terme municipal d'Elx. Dins d'aquestes tanques naturals l'activitat agrícola ha estat escassa durant molt de temps fonamentalment per la manca d'aigua. Per això, la font principal de subsistència hi era la ramaderia. Mostres d'aquesta activitat són termes com assagador, nom que els camperols de la zona donen a camins per on passa ramat i prop dels quals no es pot sembrar. Coromines (1983) diu del terme que és un cami estret per on passa el ramat $i$ en dóna l'etimologia àrab 'ala sāqa. O el terme mallà (mallada), del qual Coromines (1983) diu que és el «lloc on jeu el bestiar», i n'afegeix que a Mutxamel s'utilitza per referir-se «a un bancal de terra campa i sense arbres, si bé prou productiu...» (1963). A Bacarot també s'ha perdut el primitiu significat ramader del terme i actualment designa un bancal sense rec, o un lloc pla on es sembra però que no està preparat per al rec. Pel que hem dit, pot ser que aquesta partida amb fites naturals i tradicionalment ramadera dega el seu nom al baqar àrab, ja que és un lloc tancat on podia estar el ramat. A més de tot açò, pot reforçar aquesta hipòtesi el topònim rural d'Albacar, al terme municipal de Benimarfull, d'Alacant (Epalza, 1984: 51) que es refereix a una basseta, en una vall menuda, és a dir, també un lloc amb unes fites naturals, on beuria el ramat.

A més dels assagadors, hi ha altres topònims a Bacarot relacionats probablement també amb els camins, com ara lo Cirer i la Sega. Prop del cami vell d'Oriola, entre lo Reiet i la Secretària, trobem una casa gran, que es diu lo Cirer. Els noms precedits per l'article arcaic $/ o$, com aquest, també podrien provenir d'una antiga estructura del tipus lo de $x>10 e x>10 x$, i per tant serien molt més antics que els precedits d'el, la. Cirer és un topònim molt estés, tanmateix en aquesta zona tan seca hi ha molt pocs cirerers. Actualment la casa és deshabitada, i els habitants de les cases properes no recorden cap antic propietari amb aquest nom. A uns cent metres de la porta principal de la casa hi ha un caminet: és l'únic a la partida que creua la serra Colmenars cap a la costa, i per això devia ser molt conegut pels pastors. A més, és estret perquè és un pas per la serra. En àrab șirạt vol dir un camí estret per on calia passar per a entrar en el paradís musulmà. Un camí estret en definitiva, al qual possiblement fa referència el topònim Cirer. Poden reforçar aquesta hipòtesi els topònims Cirat, municipi de l'Alt Millars, o Ceret, capital del Vallespir, que tenen la mateixa etimologia.

El barranquet de la sega pot deure aquest nom al fet de segar-hi blat, alfals, etc., o tenir la mateixa etimologia que dóna Coromines (1985) per a assagador; 'ala săqa o ala sega, i així seria de nou un topònim referit als camins. 
Si la ramaderia ha estat important a la partida per haver estat durant molt de temps la forma de subsistència dels habitants del Bacarot, l'aigua també hi ha estat important, però per una altra raó: la seua carència. Fins 1927, que es va inaugurar el $\mathrm{Ca}$ nal de Riegos de Levante, i més tard la construcció de les centrals depuradores d'aigua, el rec de les poques terres de conreu que hi havia habilitades es feia amb l'aigua de tres pous d'aigua salabrosa o salmaia, que es troben al barranc de l'aigua amarga, a'los Flares i a la senieta. Notem l'alternança entre els termes aigua amarga i salmaia, que és un hibrid entre el terme sal i una paraula que en àrab significa aigua; mà, o mayya en plural. Així, els dos termes, aigua amarga i salmaia, tenen el mateix significat.

Prop també del cami vell d'Oriola, i a la marge dreta del barranc de les ovelles, es troba el lloc anomenat el Rincoleón o el Rincoleó. Actualment en aquell lloc es troba una depuradora amb'tes aigües de la qual es reguen les terres de la partida. També s'hi conserva un pou de vessant. No hi ha a Bacarot pous d'aigua dolça, per trobar-ne s'ha d'anar a Orito. El rec de les terres es feia tradicionalment amb aigua salmaia, i per a beure s'utilitzava l'aigua d'aquestos pous que arreplegaven l'aigua de pluja que lliscava pels vessants de llomes properes quan plovia. Se'n coneixen cinc, de pous de vessant, a la partida, i el del Rincoleón n'és un. Podria ser que el topònim tingués el seu origen en termes àrabs que es refereixen a l'aigua. En àrab ayn vol dir ullal, i 'uyūn, el plural, és una possible etimologia d'alguns topònims amb el mot lleó. Coromines (1976) diu que la paraula rincón o racó té un origen àrab: rukn, i que uen el País Valenciano, Baleares y comarca del Ebro es la expresión normal de la idea de "barranco"”. Segons tot açò podem llegir el topònim que tractem com barranc del lloc on hi ha aigua. Sanchis (1966) troba a l'Alt Maestrat un lloc anomenat riu Montlleó, topónim que pot reforçar la hipòtesi que donem.

Des del mateix nom de la partida, els possibles topònims àrabs que hem trobat estan relacionats amb aspectes importants del mode de vida i de la geografia del Bacarot. Els assagadors, lo Cirer, el barranquet de la sega, ens parlen dels camins, per on devien passar els ramats, font principal de vida dels habitants de la zona durant molt de temps, i que també està representat a topònims com barranc de les Ovelles o mallaes. I a l'aigua, un element tan escàs a Bacarot, es refereixen topònims com ara salmaia i Rincoleó.

\section{BIBLIOGRAFIA}

COROMINES, J. (1976): Diccionario Crítico Etimológico, Madrid, Gredos.

COROMINES, J. (1983-1985): Diccionari Etimológic i Complementari de la Llengua Catalana, Barcelona, Curial Edicions Catalanes.

Diccionari de la llengua catalana, 1987?, Barcelona, Diccionaris Enciclopèdia Catalana.

Diccionario ilustrado Spes latino-español, español-latino, 1978'11. Barcelona, Bibliograf.

EPALZA, M. (1984): «Funciones ganaderas de los albacares en las fortalezas musulmanas», Sharq Al-Andalus. Estudios Árabes, Alicante, pp. 47-54.

SANCHIS GUARNER, M. (1966): Contribució al Nomenclàtor geograffic del País Valencià, Institut d'Estudis Catalans, Barcelona.

Webster's New Universal Unabridged Dictionary, 1983. Dorset and Baber, Cleveland, Ohio, EUA. (Vegeu la definició del mot bachelor). 


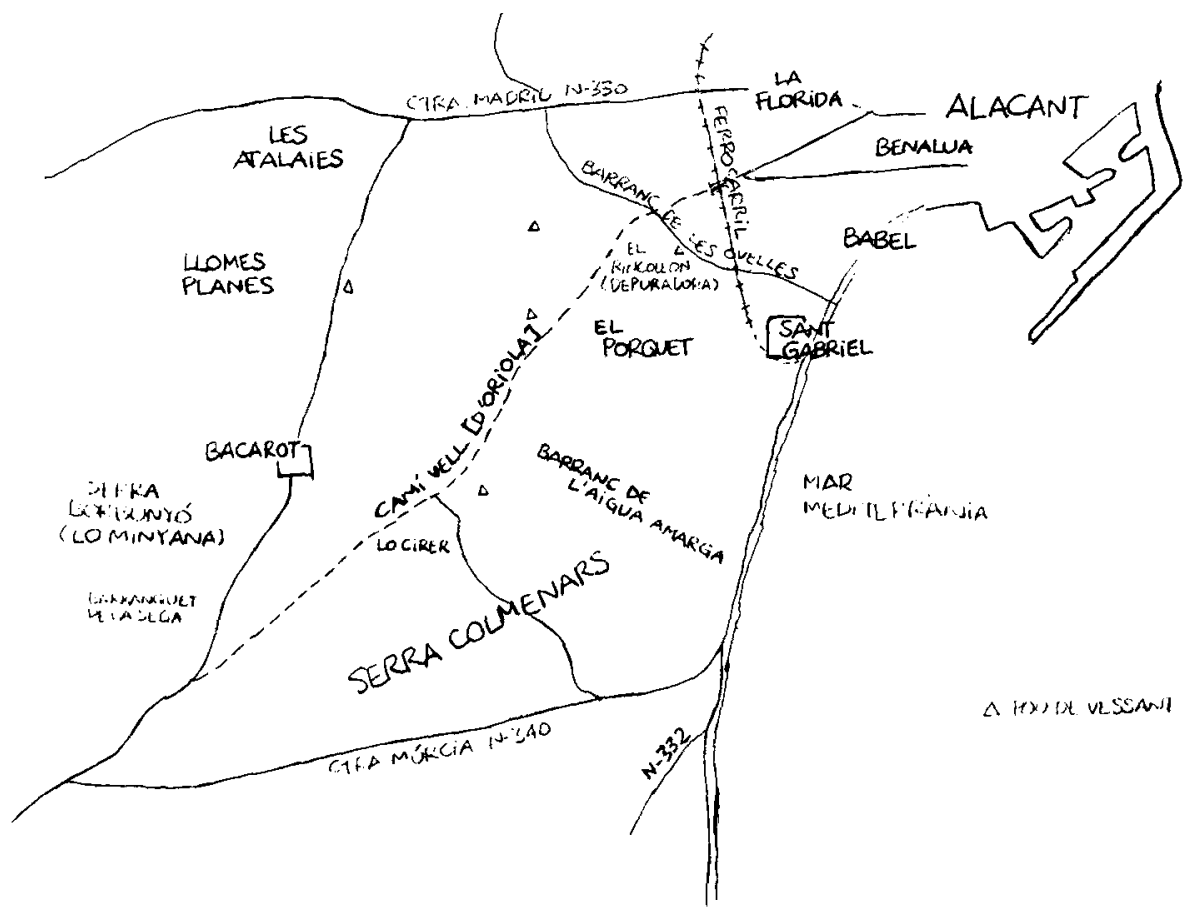

